\title{
A novel amended nitrification inhibitor confers an enhanced suppression role in the nitrification of ammonium in soil
}

\author{
Changqing Guo ${ }^{1,2} \cdot$ Hongmei Wang $^{3} \cdot$ Dianbo Zou $^{1,2} \cdot$ Yue Wang $^{1,2} \cdot$ Xiaori Han ${ }^{1,2}$
}

Received: 21 August 2021 / Accepted: 29 November 2021 / Published online: 2 January 2022

(c) The Author(s) 2021

\begin{abstract}
Purpose Nitrification inhibitor plays an important regulatory role in inhibiting the nitrification of ammonium in soils. However, most of nitrification inhibitors lack the sustainable effects in suppressing the nitrification of ammonium. In this study, a novel DMS nitrification inhibitor was prepared and tested to explore its lasting effect of nitrification suppression in black soil.

Materials and methods Both culture experiments and field trial were performed in black soils. Three kinds of nitrification inhibitors (NIs), dicyandiamide (DCD) with low bioactivity, 3,4-dimethylpyrazole phosphate (DMPP) with high bioactivity, and a novel 3,4-dimethylpyrazole sulfate zinc (DMS) with long half-life, were applied into soils, respectively, and the abundance changes of ammonia-oxidizing archaea (AOA) and ammonia-oxidizing bacteria (AOB) were investigated; then, the accumulation changes of inorganic nitrogen, nitrogen use efficiency, and crop yields were furtherly evaluated.

Results and discussions A novel DMS nitrification inhibitor with high activity and long half-life maintained a persistent effect of nitrification suppression, and remarkably increased the accumulation of ammonium nitrogen in soil, thus improving nitrogen use efficiency and crop yields. This study implies that lowering the nitrogen loss of nitrification-triggered in soil is of great importance for improving nitrogen use efficiency.

Conclusions This study provided an insight into the sustainable nitrification suppression of a novel DMS nitrification inhibitor under excessive application of nitrogen fertilizer in black soils. Compared with improving the activity, reasonably prolonging the validity of nitrification inhibitors in soil is a more important strategy increasing the sustainable effects of nitrification inhibition, and the survival period of nitrification inhibitors in soil should be a crucial factor improving nitrogen use efficiency.
\end{abstract}

Keywords Ammonia-oxidizing bacteria $\cdot$ DMS $\cdot$ Nitrification inhibitors $\cdot$ Nitrification of ammonium $\cdot$ Black soil

\section{Introduction}

Nitrogen fertilizer plays an important role in maintaining the requirement of crop nutrient and has been a major nutrition source supplying food protein and energy (Ti and Yan

Responsible editor: Jianming Xu

Xiaori Han

hanxr@syau.edu.cn

1 College of Land and Environment, Shenyang Agricultural University, No.120, Dongling Road, Shenyang 110866, China

2 Monitoring \& Experimental Station of Corn Nutrition and Fertilization in Northeast Region, Ministry of Agriculture, P.R.China, Shenyang 110866, China

3 Cnampgc Holding Limited Corporation, Entrance C, Global Finance \& News Center, No. 1 Xuanwumen Wai Avenue, Beijing 100052, China
2020). Statistics shows that a large nitrogen fertilizer input resulted in an increase of more than $40 \%$ in crop yields in the world (Li et al. 2009), while the increased grain yields could meet the food requirement of nearly $50 \%$ of the population (Erisman et al. 2008). However, the global average nitrogen fertilizer utilization rate is still maintained at a lower level, and usually ranged from 42 to $47 \%$ (Mueller et al. 2017; Zhang et al. 2015), indicating that more than $50 \%$ of nitrogen fertilizer are lost or wasted by multiple pathways such as $\mathrm{NO}^{3-}-\mathrm{N}$ leaching, nitrous oxide $\left(\mathrm{N}_{2} \mathrm{O}\right)$ emissions, and ammonia volatilization (Sutton et al. 2011; Wang et al. 2018; Zhang et al. 2019). Lower utilization rate of nitrogen fertilizer not only results in economic waste, but also triggers serious environmental problems such as water pollution, eutrophication, climate anomalies, loss of biodiversity, air pollution, and soil degradation (Galloway et al. 2004; Zhang et al. 2015; Yu et al. 2019). From 1980 to 2010, although 
the amounts of nitrogen absorption in crops have doubly increased in agricultural production in China, the input of nitrogen fertilizer was increased by threefold (Liu et al. 2016; $\mathrm{Ti}$ and Yan 2020). For improving the utilization rate of nitrogen fertilizer, the Ministry of Agriculture of China issued the "Zero Growth Plan 2020" in 2015 to reduce nitrogen fertilizer loss and ensure food security. Therefore, reasonable fertilization practice is of great importance for alleviating the environmental stress and maintaining agricultural sustainable development. Especially, with the increase of intensive agriculture production, excess application of nitrogen fertilizer has obviously lowered the soil quality. For example, as a major fertile soil resource, the black soil in the northeast of China has been facing a problem of severe soil degradation (Liang et al. 2016), both the intensive cultivation and a large input of chemical fertilizers have aggravated the loss of nitrogen in soils, and thus lowering the soil productivity in this region (Gu et al. 2018; Tong and Xu 2012; Zhu et al. 2018).

Loss pathway of nitrogen is usually related to the nitrification in soil, while nitrification is a process involving in a circle of soil nitrogen and represents an oxidation process converting ammonia into nitrite, thus eventually producing nitrates (Musiani et al. 2020). Excessive accumulation of nitrates in soil subsequently triggers nitrogen loss by leaching pathway of nitrous nitrate and nitrogen oxide emissions (Ding et al. 2021). Therefore, how to improve the utilization efficiency of nitrogen fertilizer is of great importance for reducing the loss of nitrogen in soils (Chen et al. 2015). As additive of fertilizer, nitrification inhibitors could remarkably delay the nitrification process of ammonium nitrogen in soil, and widely have been applied as an effective means lowering the loss of nitrogen and improving the utilization rate of nitrogen fertilizer as well as increasing crop yields (Di and Cameron 2012; Shi et al. 2016a, b; Gao et al. 2021).

In this study, to systematically observe the sustainable effects of a novel DMS nitrification inhibitor in soil, two traditional nitrification inhibitors, DCD with low activity and DMPP with high activity, were used as references, and applied in the soil culture and field experiment, respectively. In incubation experiment and pot culture, all of tested soils come from the same black soil as the field experiment in Jilin province in the northeast of China. Under the presence of three nitrification inhibitors, both the accumulation of inorganic nitrogen and abundance of ammonium-oxidizing bacteria (AOB) in soils were investigated; then, nitrogen use efficiency and maize yields were evaluated. This study confirmed a sustainable regulatory role of a novel nitrification inhibitor DMS in improving nitrogen fertilizer use efficiency in black soil, and provided insight into the development of novel nitrification inhibitor with persistence of nitrification inhibition, indicating that reasonable application of a novel DMS nitrification inhibitor and traditional nitrification inhibitors is of great importance for lowering the loss of nitrogen fertilizer in this region.

\section{Materials and methods}

\subsection{Preparation and identification of nitrification inhibitor}

DMS was synthesized by the methods of Adams et al. (2010) with a minor modification. Approximately $9.6 \mathrm{~g}$ of 3,4-dimethylpyrazole (DMP) was dissolved into $30 \mathrm{~mL}$ of absolute ethyl alcohol. The generating solution was slowly transferred into a beaker of $500 \mathrm{~mL}$ containing $8 \mathrm{~g}$ of anhydrous zinc sulfate of $10 \%$ to obtain a clear solution. A pH value of the solution was adjusted to 6.5 by using ammonium hydroxide, and the solid sediments with light yellow were produced. After stirring for $30 \mathrm{~min}$, suction filtration was conducted, and the filtrated product was washed and sedimented alternatively by using distilled water and ethyl alcohol for three times, respectively, then the generating target compound DMS was obtained by drying process. The elemental components of DMS were determined by using an elemental analyzer (240C PerkinElmer Inc., USA) and mainly composed of $32.86 \%$ of $\mathrm{C}, 4.25 \%$ of $\mathrm{H}$, and $15.36 \%$ of $\mathrm{N}$. The related structural formula of the compound is shown in Fig. 1.

For determining the content of DMS, this compound was dissociated by diluting with sulfuric acid; then, the DMS content in the target compound was determined by highperformance liquid chromatography (LC-20AT, Shimadzu Inc., Japan). A C18 silica gel chromatographic column (Shiseido, $250 \times 4 \mathrm{~mm}$ ) was used for the detection, while the liquid phase was composed of methanol solution and high-purity water with a ratio of $4: 6$ of methanol/water, the flow velocity was set by $1 \mathrm{~mL}$ of per minute, and the detection was performed under wavelength of $220 \mathrm{~nm}$. The effective components in DMS (i.e., DMP) accounted for $41.8 \%$, and the purity of the target compound reaches to $95.0 \%$. DCD with the purity of $99.5 \%$ and DMPP with a purity of $97 \%$ were supplied by the Chemical Institute of Jilin University, China. DMPP or DMS or DCD was mixed with ammonium sulfate (AS) of $21 \%$, and was applied in both soil culture and field experiments; all fertilizer nitrogen were applied by $1 \%, 1 \%$, and $5 \%$ of $\mathrm{NH}_{4}{ }^{+} \mathrm{N}$ in soils, respectively (O'Callaghan et al. 2010).

\subsection{Soil collection, characterization, and preparation}

Soil samples were collected from the layer of $0-20-\mathrm{cm}$ soil of farmlands in Dehui city, Jilin province, China $\left(44^{\circ} 31^{\prime} \mathrm{N}, 125^{\circ}\right.$ $43^{\prime}$ E). The soil type was classified into black soil; the basic properties of soils are shown in Table 1. 
(a)

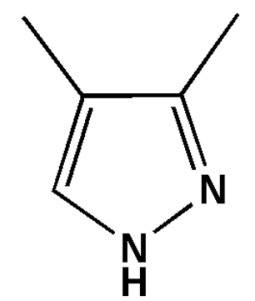

(b)

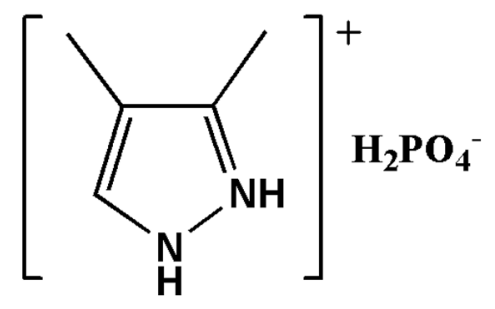

(c)

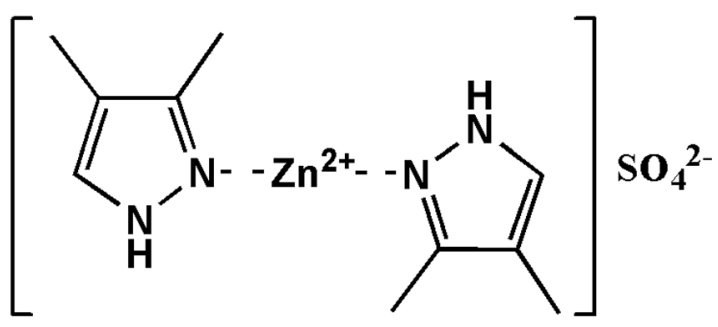

Fig. 1 Chemical structural formulas of DMP (a), DMPP (b), and DMS (c)

Natural dried soils were sieved through a sieve less than $2 \mathrm{~mm}$ and used for property analysis, and the remained soils were used for soil incubation and pot culture experiments. For both soil incubation and pot culture, the moisture in air-dry soil was maintained at the field levels, and the field moisture capacity was determined by using the column method described previously (Asher et al. 2002).

\subsection{Incubation experiment}

A soil incubation experiment was carried out in laboratory to investigate the nitrification inhibition effect of three nitrification inhibitors. The experiment was composed of four treatments including the control with $\mathrm{NH}_{4}{ }^{+}-\mathrm{N}$ of $200 \mathrm{mg} \mathrm{kg}^{-1}$ dry soil, DMPP treatment with $\mathrm{NH}_{4}{ }^{+}-\mathrm{N}$ of $200 \mathrm{mg} \mathrm{kg}^{-1}$ dry soil + DMPP $\left(1 \%\right.$ of $\left.\mathrm{NH}_{4}{ }^{+}-\mathrm{N}\right)$, DMS treatment with $\mathrm{NH}_{4}{ }^{+}-\mathrm{N}$ of $200 \mathrm{mg} \mathrm{kg}^{-1}$ dry soil + DMS ( $1 \%$ of $\left.\mathrm{NH}_{4}{ }^{+}-\mathrm{N}\right)$, and DCD with $\mathrm{NH}_{4}{ }^{+}-\mathrm{N}$ of $200 \mathrm{mg} \mathrm{kg}^{-1}$ dry soil+ DCD $\left(5 \%\right.$ of $\left.\mathrm{NH}_{4}{ }^{+}-\mathrm{N}\right)$. Each treatment was replicated by three times at least.

A total of $200.0 \mathrm{~g}$ of the air dried soil was thoroughly mixed with a composite of AS, DCD, DMPP, and DMS, respectively, and placed into a covered plastic pot of $500 \mathrm{~mL}$, and the water capacity was maintained at a level of $60 \%$ by supplement of deionized water and was similar to the field moisture contents, and the holes on the cover were punched to ensure sufficient oxygen during the incubation at $25^{\circ} \mathrm{C}$, and the amounts of water loss were supplemented in an interval of 2 days by weighing method. For soil sampling at the different periods of culture, each treatment was composed of 20 pots to ensure three replication's requirements at least. The samples were collected by four replicates after $3,6,12,24$, and 48 days of beginning incubation, respectively, and soils in each pot were blended evenly. About $100 \mathrm{~g}$ of collected soil samples were divided into two groups, then, one group was stored at $-20{ }^{\circ} \mathrm{C}$ and another was stored at $-80{ }^{\circ} \mathrm{C}$, and used to detect the contents of ammonium nitrogen or nitrate nitrogen as well as $\mathrm{AOA} / \mathrm{AOB}$ abundance, respectively.

\subsection{Pot culture experiment}

The soil samples were sieved by a sieve of $5 \mathrm{~mm}$ and put into pots with a diameter of $25 \mathrm{~cm}$ and a height of $33 \mathrm{~cm}$, and each pot was added by a mass weight of $8 \mathrm{~kg}$ dry soil. Similar to soil incubation, pot experiment was composed of four treatments, and each treatment was composed of 12 pots, and $0.15 \mathrm{~g}$ of $\mathrm{NH}_{4}{ }^{+}-\mathrm{N} \mathrm{kg}^{-1}$ dry soil of per pot was applied. The fertilizers and inhibitors were thoroughly mixed with soil samples; then, $0.1 \mathrm{~g}$ of $\mathrm{P}_{2} \mathrm{O}_{5} \mathrm{~kg}^{-1}$ dry soil in the form of monocalcium phosphate and $0.15 \mathrm{~g}$ of $\mathrm{K}_{2} \mathrm{O} \mathrm{kg}^{-1}$ dry soil in the form of potassium chloride were applied into each pot, respectively. Quantitative supplement of water was performed to maintain a moisture content of $60 \%$ which is basically identical with the field water capacity during wheat growth period. Total of 15 seeds of spring wheat (Triticum aestivum L. cv. Shenmian\#26) were sown in each pot, and the seedlings of 6 plants of per pot were fixed after 20 days of germination and seedling establishment.

A destructive sampling of soils and plants was finished at the wheat seedling period, stem elongation period, pustulation period, and maturity period, which are represented by 25,58 , 85, and 125 days after sowing, respectively. The fresh soil samples were packed with ice pack and transported to the laboratory, and then passed through a sieve of $2 \mathrm{~mm}$ after removing debris. A part of the samples was stored at $-20^{\circ} \mathrm{C}$ for chemical analysis, and the remaining part was stored at $-80^{\circ} \mathrm{C}$ for DNA extraction. For molecular biological analyses, about $10 \mathrm{~g}$ of fresh soil was collected from each sample.

Table 1 Basic chemical properties of the tested soils

\begin{tabular}{lllllllll}
\hline Soil type & $\begin{array}{l}\text { Total } \mathrm{N}(\mathrm{g} \\
\left.\mathrm{kg}^{-1}\right)\end{array}$ & $\begin{array}{l}\text { Available } \mathrm{N} \\
\left(\mathrm{mg} \mathrm{kg}^{-1}\right)\end{array}$ & $\begin{array}{l}\mathrm{NH}_{4}^{+}-\mathrm{N}(\mathrm{mg} \\
\left.\mathrm{kg}^{-1}\right)\end{array}$ & $\begin{array}{l}\mathrm{NO}_{3}^{-}-\mathrm{N}(\mathrm{mg} \\
\left.\mathrm{kg}^{-1}\right)\end{array}$ & $\begin{array}{l}\text { Olsen-P }(\mathrm{mg} \\
\left.\mathrm{kg}^{-1}\right)\end{array}$ & $\begin{array}{l}\text { Available } \mathrm{K} \\
\left(\mathrm{mg} \mathrm{kg}^{-1}\right)\end{array}$ & $\begin{array}{l}\mathrm{pH}\left(\mathrm{H}_{2} \mathrm{O}\right) \\
\text { Organic matter } \\
\left(\mathrm{g} \mathrm{kg}^{-1}\right)\end{array}$ \\
\hline Black soil & 1.05 & 134.56 & 8.17 & 21.97 & 39.45 & 178.56 & 6.52 & 23.21 \\
\hline
\end{tabular}


Plant samples were dried at $65^{\circ} \mathrm{C}$ for $48 \mathrm{~h}$ and used for biomass determination. The harvested stems, leaves, and grains of plants at the maturity period were dried and separately weighted. Plant samples were homogeneously ground and used for determining $\mathrm{N}$ contents by the Kjeldahl method (Tan 2005).

\subsection{Field experiment}

The field experiment was conducted by using the same soils as the incubation or pot experiment. The testing site is located at the temperate region with an average annual precipitation of $516 \mathrm{~mm}$ and average air temperature of $4.9^{\circ} \mathrm{C}$. The crop growth period is mainly gathered in the period from April to September, which annually has an average temperature of $16{ }^{\circ} \mathrm{C}$ and average precipitation of $180.5 \mathrm{~mm}$.

Field trial was composed of three treatments including the control with only addition of urea, DMPP with urea $(1 \%$ of urea-N), and DMS with urea $(1 \%$ of urea-N). The application doses of $\mathrm{N}, \mathrm{P}$, and $\mathrm{K}$ in each treatment were performed by $\mathrm{N}$ of $210 \mathrm{~kg} \mathrm{ha}^{-1}, \mathrm{P}_{2} \mathrm{O}_{5}$ of $90 \mathrm{~kg} \mathrm{ha}^{-1}$, and $\mathrm{K}_{2} \mathrm{O}$ of $90 \mathrm{~kg} \mathrm{ha}^{-1}$, respectively. Urea, monocalcium phosphate, and potassium chloride were used as testing fertilizers.

Both fertilizers and nitrification inhibitors were ground into powder and completely mixed as described in the culture experiments, then evenly applied into the position of $10 \mathrm{~cm}$ apart from the row ridge by incorporating a depth of about $5 \mathrm{~cm}$. Each treatment was composed of three independent plots, and each plot was designed by $4 \mathrm{~m} \times 10 \mathrm{~m}$, and corn was sown by a seeding density of 4500 plants of per ha on May 7, 2015. The corn harvesting was performed by hand-cutting on October 5, 2015.

\subsection{Soil parameter analysis}

To determine the concentrations of ammonium nitrogen $\left(\mathrm{NH}_{4}{ }^{+}-\mathrm{N}\right)$ and nitrate nitrogen $\left(\mathrm{NO}_{3}{ }^{-}-\mathrm{N}\right)$ in soil, fresh soil samples were extracted with $0.01 \mathrm{~mol} \cdot \mathrm{L}^{-1} \mathrm{CaCl}_{2}$ solution; then, the concentrations of ammonium- and nitrate-nitrogen in leaching liquor were measured by an analyzer of AA3 continuous-flow (Bran Luebbe, Germany) according to the described method in Ghani et al. (2007).

Soil $\mathrm{pH}$ in the solution of 1:2.5 ratio of water versus soil was determined by a glass electrode. Dried soil samples were digested by the standard procedures and used for nitrogen measurement by a Kjeldahl apparatus (Tan 2005). Soil available $\mathrm{K}$ was extracted with ammonium acetate solution and determined through flame photometry (Isaac and Kerber 1971). Soil Olsen $\mathrm{P}$ was extracted by using $\mathrm{NaHCO}_{3}(\mathrm{pH}$ 8.5 ) of $0.5 \mathrm{~mol}$ and determined by molybdenum antimony blue colorimetry. Soil organic matter content was determined through the potassium dichromate digestion method (Tan 2005).

\subsection{Quantitative PCR of amoA genes in soils}

Total soil DNA extraction was implemented by using the PowerSoil@ DNA Isolation Kit according to the manufacturer's instructions (MobioLaboratories, USA). Copy numbers of archaeal and bacterial genes were determined by using quantitative PCR SYBR Green-based chemistry and a realtime PCR system (Rotor-Gene Q, Qiagen, Inc., Germany) (Limpiyakorn et al. 2011).

In brief, archaeal amoA genes were quantified by qPCR with a pair of primers, Arch-amoAF and Arch-amoAR, and an amplification fragment of $635 \mathrm{bp}$ was obtained. While a fragment of approximately $490 \mathrm{bp}$ expressing the amoA gene was generated by using the specific primers of AmoA$1 \mathrm{~F}$ and amoA-2R (Table 2). Cycling procedures used for quantitative PCR detection were performed. In brief, a total of $20 \mu \mathrm{L}$ PCR reaction system contained $2 \mu \mathrm{L}$ of template DNA, $10 \mu \mathrm{L}$ of $2 \times$ SYBR ${ }^{\circledR}$ Premix Ex Taq ${ }^{\mathrm{TM}}, 0.8 \mu \mathrm{L}$ of forward and $0.8 \mu \mathrm{L}$ of reverse primers, and $6.4 \mu \mathrm{L}$ of sterilized deionized water in each tube; then, the PCR thermal cycle was performed by the following steps: initial denaturation at $94{ }^{\circ} \mathrm{C}$ for $5 \mathrm{~min}$ and degeneration at $94{ }^{\circ} \mathrm{C}$ for $10 \mathrm{~s}$ with 40 cycles of $55^{\circ} \mathrm{C}$ for $15 \mathrm{~s}, 72{ }^{\circ} \mathrm{C}$ for $45 \mathrm{~s}$, and $72{ }^{\circ} \mathrm{C}$ for $10 \mathrm{~min}$. The generated $a m o A$ gene plasmids representing the AOB and AOA in clone library were diluted by $10^{5}, 10^{6}$, $10^{7}, 10^{8}$, and $10^{9}$ folds to generate standard curves by cascading dilution method. Specific amplification was checked by melting curve analysis and agarose gel electrophoresis.

\subsection{Nitrogen use efficiency calculation}

The components of $\mathrm{N}$ efficiency were determined by a previous method (Guillaumes and Villar 2004). For the pot experiment, nitrogen uptake (NUp) $\left(\mathrm{g} \mathrm{pot}^{-1}\right)$ representing total amounts of $\mathrm{N}$ in plant were estimated by using the $\mathrm{N}$ concentrations in grain and straw, while nitrogen utilization efficiency was determined by a formula of NUE $(\%)=\mathrm{N}$ uptake fertilized crop $/ \mathrm{N}_{\text {applied }} \times 100 \%$, and apparent use efficiency of $\mathrm{N}$ fertilizer was estimated by a formula of AUN $(\%)=\left(\mathrm{N}_{\text {uptake }}\right.$ fertilized crop $-\mathrm{N}$ uptake unfertilized crop $) /$ $\mathrm{N}_{\text {applied }} \times 100 \%$. For the field experiment, the following components of $\mathrm{N}$ efficiency were determined by using the crop yield. Nitrogen partial factor productivity was determined

Table 2 qRT-PCR primers used for amplification of functional target genes

\begin{tabular}{lll}
\hline Target gene & Primer & Primer sequence, 5'-3' \\
\hline AOB amoA & amoA-lF & GGGGTTTCTACTGGTGGT \\
& amoA-2R & CCCCTCKGSAAAGCCTTCTTC \\
AOA amoA & Airch-amoAF & STAATGGTCTGGCTTAGACG \\
& Airch-amoAR & GCGGCCATCCATCTGTATGT \\
\hline
\end{tabular}


by a formula of NFP $\left(\mathrm{kg} \cdot \mathrm{kg}^{-1}\right)=$ Yield fertilized crop $/ \mathrm{N}_{\text {applied, }}$ and nitrogen agronomic efficiency was estimated by a formula

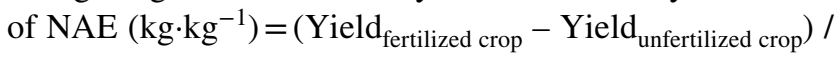
$\mathrm{N}_{\text {applied. }}$

\subsection{Statistical analyses}

Statistical analyses were carried out by using the SPSS 18.0 software package for Windows, and significant difference identification was performed by one-way ANOVA with the least significant difference (LSD) method at a level of less than 5\%. The relationship between the accumulation amounts of $\mathrm{NO}_{3}{ }^{-}-\mathrm{N}$ and the copy numbers of bacterial or archaeal $a m o A$ genes in soils was assessed by using linear regression analysis of Origin 8.

\section{Results and discussions}

\subsection{Nitrification inhibitors remarkably inhibited the nitrification of ammonium in soil}

Nitrification inhibitors generally function in suppressing the oxidation of ammonia monooxygenase (AMO) (Di and Cameron 2011), thus delaying the conversion of ammonium $\mathrm{NH}_{4}{ }^{+}$to nitrite $\left(\mathrm{NO}_{2}^{-}\right)$and reducing the accumulation of nitrate in soils (Florio et al. 2014). In this study, for investigating the suppression effect of nitrification inhibitors on the nitrification of ammonium, both soil incubation and pot experiment were performed to determine the accumulation profiles of ammonium and nitrate nitrogen in soils. As shown in Fig. 2a, after 48 days of short-term soil incubation or 125 days of long-term pot experiment, the ammonium nitrogen content in soil of the control treatment was obviously decreased, while three treatments with nitrification inhibitor demonstrated higher contents of the ammonium nitrogen within 48 days of soil incubation comparing to the control. However, in the case of pot experiment, the treatments with nitrification inhibitor still revealed an increase of the ammonium nitrogen after 83 days of culture comparing to the control (Fig. 2b). Data shows that the contents of ammonium nitrogen in the treatments with nitrification inhibitor were increased by tenfold after 12 days of soil incubation, while the ammonium nitrogen was only increased by threefold after 57 days of pot culture comparing to the control, respectively.

In the case of soil incubation experiment, three kinds of nitrification inhibitors demonstrated differential effects in suppressing the nitrification of ammonium. Both the DMPP and DMS treatments remarkably increased the accumulation of ammonium nitrogen in soils comparing to the DCD treatment. Particularly, when the incubation time was prolonged, this difference in ammonium accumulation became more significant after 24 days of soil incubation (Fig. 2a). Data shows that the DMPP treatment and DMS treatment, respectively, accumulated $140.40 \mathrm{mg} \mathrm{kg}^{-1}$ and $123.15 \mathrm{mg} \mathrm{kg}^{-1}$ of ammonium nitrogen ammonium nitrogen in soils, while the DCD treatment only showed an accumulation of $108.84 \mathrm{mg} \mathrm{kg}^{-1}$ of ammonium nitrogen $(P<0.05)$, but the accumulation of ammonium nitrogen in the treatments with nitrification inhibitor was significantly higher than $10.62 \mathrm{mg} \mathrm{kg}^{-1}$ dry soil of ammonium nitrogen in the control. After 48 days of soil incubation, the DMS treatment showed $74.52 \mathrm{mg} \mathrm{kg}^{-1}$ dry soil of ammonium nitrogen, which was higher than $72.36 \mathrm{mg} \mathrm{kg}^{-1}$ dry soil in the DMPP treatment and $42.35 \mathrm{mg} \mathrm{kg}^{-1}$ dry soil in the DCD treatment $(P<0.05)$. Similar differences were also observed in the pot experiment of 83 days (Fig. 2d). Especially, accumulation of ammonium nitrogen in the DMS treatment reached the highest level and was increased by $62.18 \%$ comparing to the DMPP treatment, but increased by $17.16 \%$ comparing to the DCD treatment $(P<0.05)$. In contrast, the control treatment showed an increasing trend of soil nitrate nitrogen after 12 days of early culture stage and then demonstrated a decrease after 57 days of the late culture stage. As shown in Fig. 2b, e, the nitrate nitrogen in the control treatment reached the highest peak of $185.75 \mathrm{mg} \mathrm{kg}^{-1}$ dry soil after 12 days of culture, and still was maintained at a level of $181.95 \mathrm{mg}^{-1}$ dry soil even after 57 days of culture.

In this study, three nitrification inhibitors effectively inhibited the generation of nitrate in the cultured soil of 12 days. Although the contents of nitrate in the nitrification inhibitor treatments slowly increased, the overall level of nitrate was still significantly lower than that in the control after 12 days of culture, while the nitrate contents in the treatments with nitrification inhibitors were less than $10 \%$ of the highest peak value of nitrate in the control (Fig. 2b). Measurements show that nitrification inhibitor treatments revealed a significant difference in suppressing the nitrification after 24 days of culture, both the DMPP and DMS treatments demonstrated a similar effect, and the contents of nitrate in these two treatments were lowered by $37 \%$ comparing to the DCD treatment, and lowered by $74 \%$ comparing to the control after 48 days of culture. Data shows that the DMS treatment accumulated $90.34 \mathrm{mg} \mathrm{kg}^{-1}$ of nitrate in soil, which basically was identical with $92.90 \mathrm{mg} \mathrm{kg}^{-1}$ in the DMPP treatment, while the DCD treatment accumulated $110.43 \mathrm{mg} \mathrm{kg}^{-1}$ of nitrate in soil $(P<0.05)$ (Fig. 2b).

Pot experiment planting wheat showed that after 57 days of culture, the treatments with nitrification inhibitors significantly lowered the accumulation of nitrate than the control. The nitrification inhibitor treatments did not demonstrate differences in the accumulation of nitrate after 28 days of culture, but the accumulation of nitrate was lowered by $35 \%$ comparing to the control. Data shows that the DMS treatment demonstrated the best nitrification 

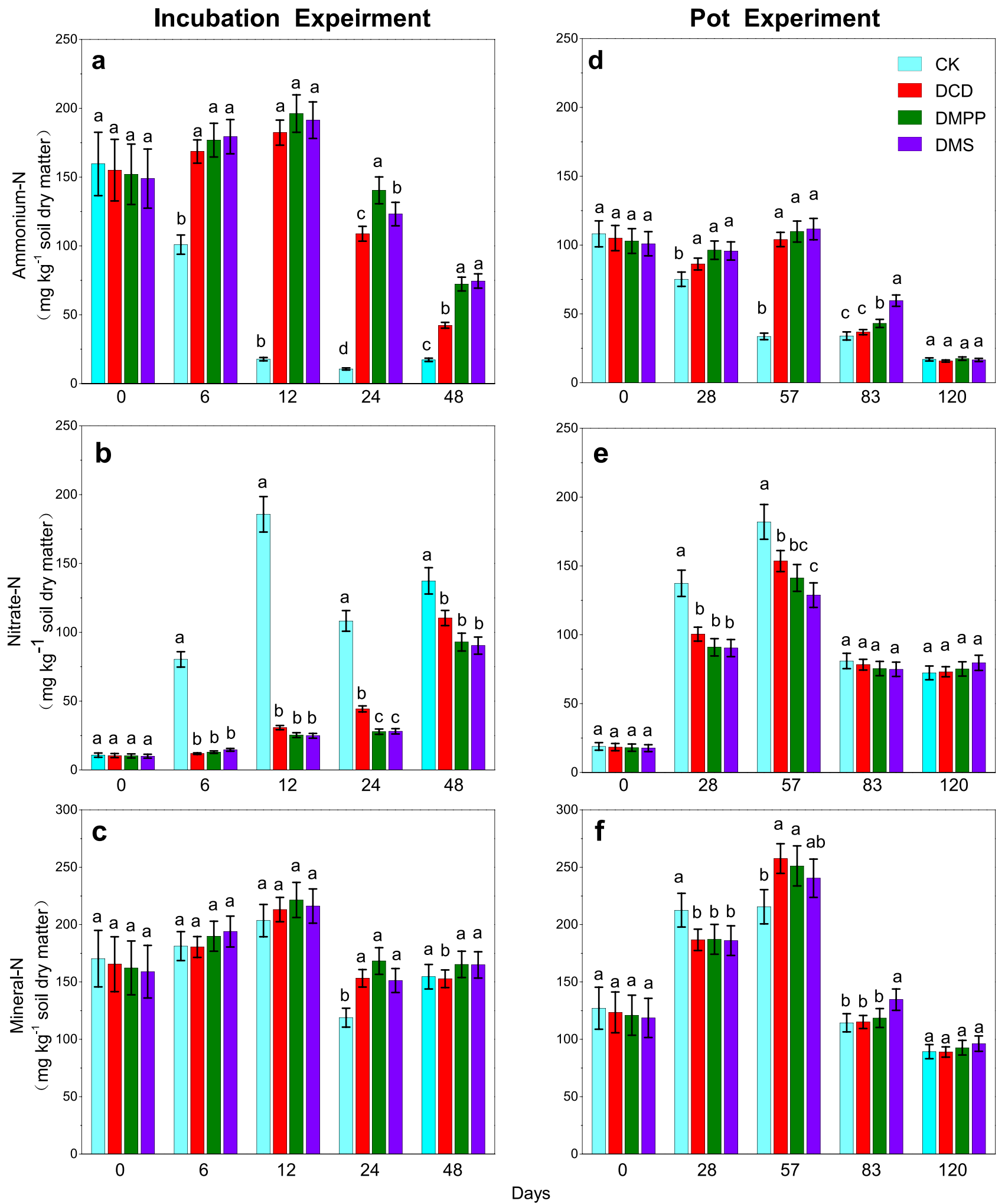

Fig. 2 The dynamic characteristics of soil nitrogen. (a, d) $\mathrm{NH}_{4}{ }^{+}-\mathrm{N}$; $\left(\right.$ b, e) $\mathrm{NO}_{3}{ }^{-} \mathrm{N} ;(\mathbf{c}, \mathbf{f})$ mineral $\mathrm{N}\left(\mathrm{NO}_{3}{ }^{-}-\mathrm{N}+\mathrm{NH}_{4}{ }^{+}-\mathrm{N}\right)$ in black soils from incubation experiment and pot culture. Bars represent the stand-

ard errors of the mean $(n=3)$. The different lowercase letters indicate significant difference at the level of less than $5 \%$ 
inhibition effect $(P<0.05)$. The contents of nitrate in the DMS treatment were maintained at a lower level of $128.78 \mathrm{mg} \mathrm{kg}^{-1}$, while the DMPP treatment demonstrated an accumulation of $141.29 \mathrm{mg} \mathrm{kg}^{-1}$ of nitrate, and the DCD treatment accumulated $153.54 \mathrm{mg} \mathrm{kg}^{-1}$ of nitrate in soils (Fig. 2). Comparing to the peak value of nitrate in the control, the DMS treatment lowered $29.22 \%$ of nitrate, the DMPP treatment lowered $22.35 \%$ of nitrate, and the DCD treatment lowered $15.62 \%$ at this stage, but all treatments basically accumulated identical levels of nitrate after 57 days of culture (Fig. 2).

Pot experiment showed that the treatment with DMS nitrification inhibitor revealed more accumulation of ammonium nitrogen in soil after 83 days, and significantly lowered the contents of nitrate after 57 days comparing to the DMPP treatment $(P<0.05)$. Generally, nitrification inhibitors could significantly increase the contents of ammonium in soils, thus triggering the evaporation of ammonium and lowering the contents of nitrate in soils (Davies and Williams 1995; Menéndez et al. 2006) despite of differences in soil texture and $\mathrm{pH}$ values (Zerulla et al. 2001).

Although total inorganic nitrogen in soil was not changed under the presence of nitrification inhibitor after 24 days or 48 days of culture (Fig. 2c, f), the nitrification inhibitor treatments increased the accumulation of inorganic nitrogen of more than $30 \%$ after 24 days or 48 days of soil culture comparing to the control. In the case of 48-day culture, the contents of inorganic nitrogen in the DMPP and DMS treatments were $165.26 \mathrm{mg} \mathrm{kg}^{-1}$ and $164.86 \mathrm{mg} \mathrm{kg}^{-1}$ dry soil, respectively, while the DCD treatment maintained at a level of $152.78 \mathrm{mg} \mathrm{kg}^{-1}$ of inorganic nitrogen which is similar to $154.57 \mathrm{mg} \mathrm{kg}^{-1}$ dry soil of inorganic nitrogen in the control. Inorganic nitrogen was increased by $8.07 \%$ in the DMS and by $7.81 \%$ in the DMPP treatment comparing to the control, respectively (Fig. 2c). Pot experiment with planting wheat showed that the treatments with nitrification inhibitor increased $34.09 \%$ of soil inorganic nitrogen after 57 days, and all treatments showed a peak value of inorganic nitrogen, but no significant differences in inorganic nitrogen between nitrification inhibitor treatments were observed. However, after 83 days of culture, the contents of soil inorganic nitrogen in both the DMPP and DCD treatments rapidly declined, and basically were maintained at a similar level to that in the control; only the DMS treatment increased accumulation of inorganic nitrogen of $17.68 \%$ comparing to the control, indicating that a novel DMS revealed long-lasting effect in inhibiting nitrification than DMPP (Fig. 2f).

In this study, a novel high-activity and long-lasting DMS nitrification inhibitor remarkably suppressed the nitrification of ammonium in black soil, thereby effectively inhibiting the production of nitrate nitrogen and increasing the accumulation of ammonium nitrogen in soils after 40 days of soil culture (Fig. 2a) or after 58 days of plant culture (Fig. 2d).
This result is consistent with the previous reports that the nitrification inhibitors played an important role in inhibiting nitrification in different soils (Xu et al. 2001; Gong et al. 2013; Zhou et al. 2020). Our study shows that both the soil incubation and pot experiment accumulated more ammonium nitrogen and lowered the loss of nitrate in soils because of the presence of nitrification inhibitors, thus increasing the accumulation of ammonium- and nitrate-nitrogen in soils (Fig. 2c, f), which is the same as previously reported by $\mathrm{Wu}$ et al. (2007), indicating that application of a novel DMS nitrification inhibitor in black soils could effectively increase the accumulation of ammonium nitrogen.

\subsection{Nitrification inhibitors increased the amounts of $A O A$ and lowered abundance of $A O B$ in soil}

To evaluate the effects of a novel DMS on the key microorganisms involving in the nitrification reactions, the abundance changes of $\mathrm{AOB}$ and $\mathrm{AOA}$ in soils were investigated by the fluorescent quantitative PCR (Figs. 2 and 3). Data shows that the number of gene copies of ammonia oxide bacteria (AOA) was ranged from $2.3 \times 10^{7}$ to $1.15 \times 10^{8} \mathrm{~g}^{-1}$ dry soil, and initial value was tenfold of AOB in soil. Although the AOA abundance in the two trials was increased gradually after nitrogen fertilization, but not affected by the nitrification inhibitors (Fig. 2b, d). Statistics shows that more enrichment of $\mathrm{AOB}$ is an important factor affecting nitrate accumulation in soil. For example, the amounts of soil nitrate showed a significant positive linear correlation with soil bacterial amoB gene copy number $(P<0.01)$ (Fig. 3 ), but no significant correlation with copy number of archaeal amoA gene in soils although no data was shown, indicating that the AOB bacteria abundance is a key factor reflecting the nitrification process in soil.

Data shows that the number of $a m o A$ gene copies of AOB was ranged from $2.90 \times 106$ to $527 \times 108 \mathrm{~g}^{-1}$ dry soil. In the case of soil incubation, the abundance of AOB in the control rapidly was increased by tenfold after fertilization and maintained at a level of $9.20 \times 107 \mathrm{~g}^{-1}$ dry soil comparing to the abundance value of AOB after 6 days of soil incubation (Fig. 3a), indicating that nitrification inhibitor treatments obviously inhibited the growth of AOB in soils. Measurement showed that the DCD treatment revealed an AOB abundance of $51.54 \%$ comparing to the control after 24 days of culture, but after 48 days of soil incubation, the same treatment accounted for $70.11 \%$ of the abundance of AOB in the control. However, the DMS treatment only accounted for $16.72 \%$ of AOB abundance in the control, while AOB abundance in the DMPP treatment also was decreased and only accounted for $13.57 \%$ of that in the control after 24 days of soil incubation. With prolonging culture time, the AOB abundance in the DMS treatment accounted for $31.69 \%$ of that in the control and accounted for $32.34 \%$ 

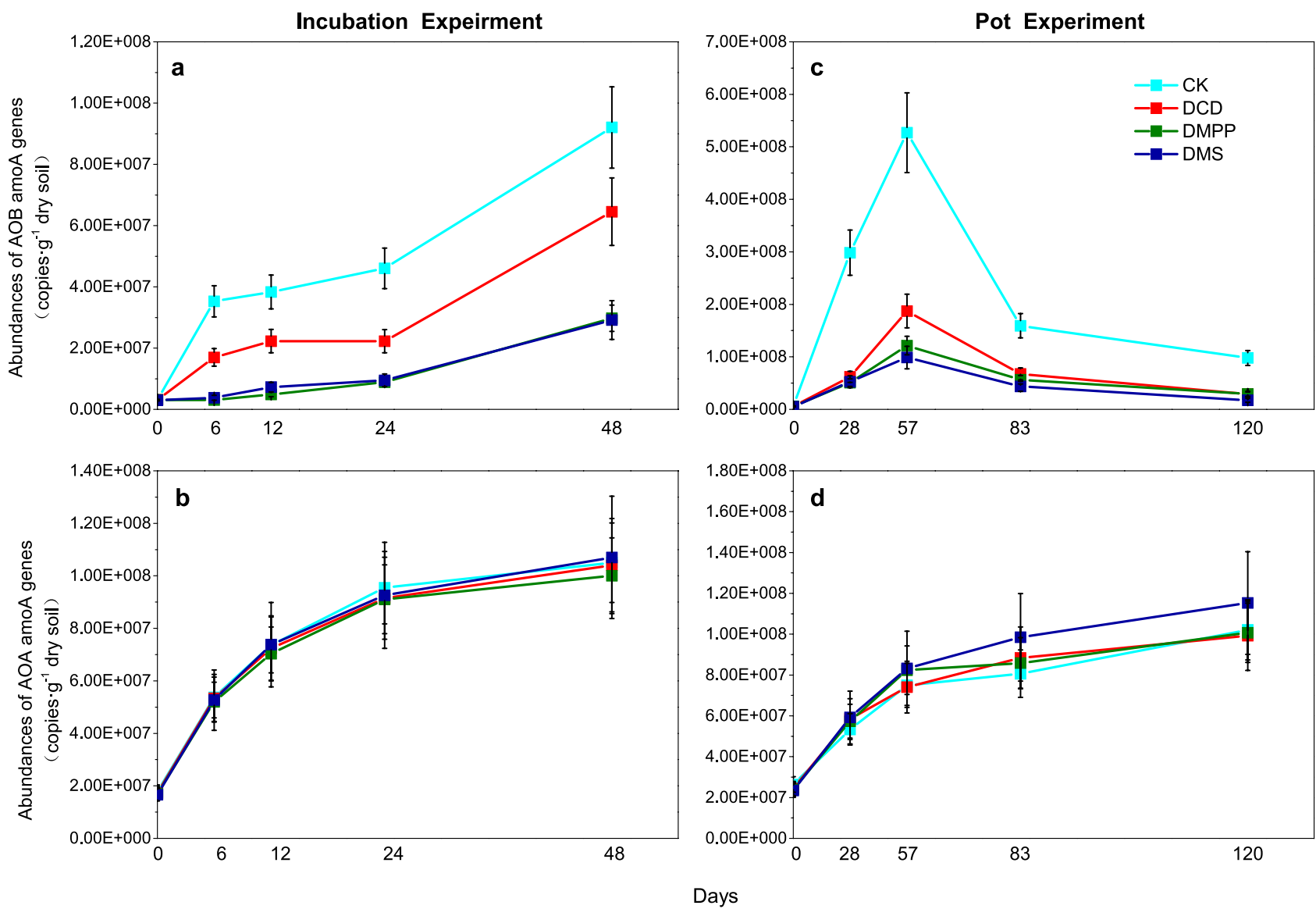

Fig. 3 Bacterial and archaeal $a m o A$ gene copies in black soil from both incubation (a, c) and pot experiment (b, d). Bars represent the standard errors of the mean $(n=3)$

of that in the DMPP treatment after 48 days, showing that novel DMS nitrification inhibitor exhibited the best effect in suppressing the bacteriogenic growth (Fig. 3a).

Pot experiment showed that all treatments revealed a peak of AOB abundance between 28 and 57 days of culture, then demonstrated a rapid decease. Data shows that the control enriched an AOB abundance of $5.27 \times 10^{8} \mathrm{~g}^{-1}$ dry soil after 57 days of culture and resulted in an increase of 5.38-fold in the AOB abundance comparing to the measurement value after 120 days of culture. All of nitrification inhibitors could effectively inhibit the growth of AOB, while the DMS treatment demonstrated the lowest abundance of $\mathrm{AOB}$, and only accounted for $20.41 \%$ of average abundance value of AOB in the control. Average abundance value of AOB in both the DMPP and DCD treatments accounted for $26.35 \%$ and $32.08 \%$ of that in the control, respectively, and a significant AOB peak appeared at the 57 th day $(P<0.05)$. Using the abundance value of AOB in the control as $100 \%$, the DMS treatment showed the lowest abundance value of $18.73 \%$ AOB, which was significantly lower than $23.05 \%$ in the
DMPP and $35.55 \%$ in the DCD treatments (Fig. 3c). This suggests that nitrification inhibitors affected the abundance of ammonia-oxidizing bacteria and ammonia-oxidizing archaea in soils. Studies have shown that nitrification inhibitors could effectively inhibit the growth of soil AOB and mainly function by regulating soil $\mathrm{N}$ transformation (Shi et al. 2017; Chen et al. 2019; Fan et al. 2019). In this study, the novel DMS nitrification inhibitor significantly inhibited the abundance of AOB and revealed a stable-lasting nitrification suppression effect in black soil, indicating that DMS plays an important regulatory role in effectively inhibiting the rapid growth of AOB bacteria (Fig. 3a, c) (Florio et al. 2014; Shi et al. 2017).

In our study, the increasing growth of AOA of fertilizationtriggered was not affected by nitrification inhibitors (Fig. 3b, d), and confirmed by previous reports (Kleineidam et al. 2011; Gong et al. 2013; Chen et al. 2015) because AOA possibly demonstrates the insensitivity to the nitrification inhibitors (He et al. 2007). Report also showed that the abundance of AOB was positively linearly correlated 


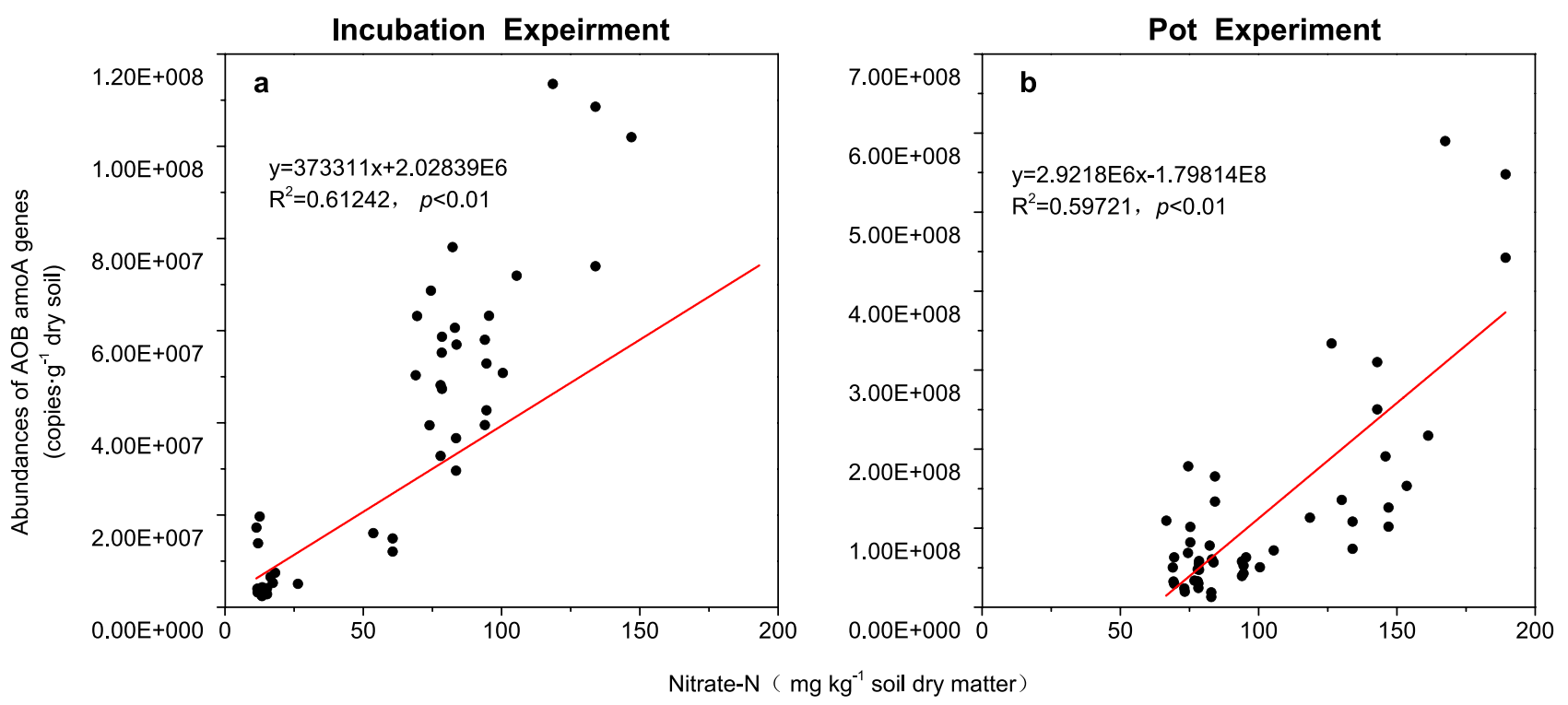

Fig. 4 Relationships between the soil $\mathrm{NO}_{3}{ }^{-}-\mathrm{N}$ contents and the abundance of ammonia oxidizing bacteria (AOB). (a) An incubation experiment and (b) a pot experiment $(n=3)$

with the accumulation of nitrate nitrogen in soil, while the abundance of AOA has no correlation with nitrate nitrogen (Gong et al. 2013). Studies have shown that the nitrification of ammonium nitrogen in soil is affected by the AOB abundance (Shen et al. 2008; Xia et al. 2011), and that the loss of $\mathrm{N}_{2} \mathrm{O}$ of AOA growth-triggered is significantly lower than that of AOB (Hink et al. 2017), indicating that the nitrification process is mainly controlled by the abundance of AOB. Wang et al. (2019) found that AOB revealed a great potential in suppressing the nitrification by investigating the soils of six types from different regions in China. In this study, both soil incubation and pot experiments showed that the abundance of amoA genes reflecting the number of $\mathrm{AOB}$ and the contents of nitrate nitrogen revealed a significant positive correlation at the level of less than 0.01 (Fig. 4), suggesting that the nitrification process in black soil is majorly regulated by the abundance of AOB, and the application of nitrification inhibitors on black soil can effectively function by regulating soil nitrogen conversion.

\subsection{Nitrification inhibitors are beneficial to increasing crop yield by promoting nitrogen use efficiency}

For determining whether the nitrification plays regulatory role in improving nitrogen use efficiency, nitrogen use efficiency in wheat or maize was investigated by pot experiment or field experiment. Measurements showed that nitrification inhibitor treatments remarkably increased the crop yield, nitrogen absorption, and nitrogen use efficiency. Particularly, fertilizer apparent use efficiency was increased by $42-66 \%$, while nitrogen fertilizer use efficiency was increased by 12.5-17.5\% comparing to the control (Table 4). The DMS treatment revealed the highest grain yield of $11.38 \mathrm{~g}$, biomass of $32.29 \mathrm{~g}$, and nitrogen absorption of $0.75 \mathrm{~g}$ of per pot, while the grain yield in the DMS treatment was increased by $32.63 \%$ comparing to the control and by $14.26 \%$ comparing to the DCD treatment, respectively (Table 3). Apparent utilization rate of nitrogen fertilizer in the DMS treatment

Table 3 Nitrogen use efficiency and yield responses of Nis-mediated in pot experiment

\begin{tabular}{lclllll}
\hline Treatment & Grain yield $\left(\mathrm{g} \cdot \mathrm{pot}^{-1}\right)$ & Biomass yields $\left(\mathrm{g} \cdot \mathrm{pot}^{-1}\right)$ & $\begin{array}{l}\text { The rate of } \\
\text { grain increase } \\
(\%)\end{array}$ & NUA $\left(\mathrm{g} \cdot \mathrm{pot}^{-1}\right)$ & $\begin{array}{l}\text { Apparent use efficiency } \\
\text { of N fertilizer }(\%)\end{array}$ & $\begin{array}{l}\text { Nitrogen use efficiency } \\
(\%)\end{array}$ \\
\hline DMPP & $11.16 \pm 0.44 \mathrm{ab}$ & $31.33 \pm 2.98 \mathrm{a}$ & $30.07 \%$ & $0.74 \pm 0.02 \mathrm{a}$ & $19.00 \pm 0.58 \mathrm{ab}$ & $46.33 \pm 1.45 \mathrm{a}$ \\
$\mathrm{DMS}$ & $11.38 \pm 0.46 \mathrm{a}$ & $32.29 \pm 2.19 \mathrm{a}$ & $32.63 \%$ & $0.75 \pm 0.03 \mathrm{a}$ & $20.16 \pm 0.67 \mathrm{a}$ & $47.00 \pm 1.53 \mathrm{a}$ \\
DCD & $9.96 \pm 0.29 \mathrm{~b}$ & $31.26 \pm 2.53 \mathrm{a}$ & $16.08 \%$ & $0.72 \pm 0.03 \mathrm{ab}$ & $17.46 \pm 0.67 \mathrm{~b}$ & $44.67 \pm 1.76 \mathrm{ab}$ \\
$\mathrm{CK}$ & $8.58 \pm 0.34 \mathrm{c}$ & $30.30 \pm 2.59 \mathrm{a}$ & - & $0.64 \pm 0.02 \mathrm{~b}$ & $12.23 \pm 0.33 \mathrm{c}$ & $40.00 \pm 1.53 \mathrm{~b}$ \\
\hline
\end{tabular}

The different lowercase letters indicate a significant difference between different treatments at a level of less than 5\% for each time point 
Table 4 Nitrogen efficiency and yield responses of Nis-mediated in the field trial

\begin{tabular}{lccccc}
\hline Treatment & Grain yield $\left(\mathrm{t} \cdot \mathrm{hm}^{-2}\right)$ & Biomass yield $\left(\mathrm{t} \cdot \mathrm{hm}^{-2}\right)$ & $\begin{array}{l}\text { Nitrogen partial factor } \\
\text { productivity }\left(\mathrm{kg} \cdot \mathrm{kg}^{-1}\right)\end{array}$ & $\begin{array}{l}\text { Nitrogen agronomic } \\
\text { efficiency }\left(\mathrm{kg} \cdot \mathrm{kg}^{-1}\right)\end{array}$ & $\begin{array}{l}\text { The rate of } \\
\text { yield increase } \\
(\%)\end{array}$ \\
\hline DMPP & $12.14 \pm 0.31 \mathrm{a}$ & $22.58 \pm 0.57 \mathrm{a}$ & $57.81 \pm 4.16 \mathrm{a}$ & $15.05 \pm 1.08 \mathrm{a}$ & $23.75 \%$ \\
DMS & $12.25 \pm 0.26 \mathrm{a}$ & $22.82 \pm 0.47 \mathrm{a}$ & $58.33 \pm 4.98 \mathrm{a}$ & $15.57 \pm 1.33 \mathrm{a}$ & $24.87 \%$ \\
CK & $9.81 \pm 0.26 \mathrm{~b}$ & $19.85 \pm 0.51 \mathrm{~b}$ & $46.71 \pm 3.78 \mathrm{~b}$ & $3.95 \pm 0.32 \mathrm{~b}$ \\
\hline
\end{tabular}

The different lowercase letters indicate a significant difference between different treatments at a level of less than 5\% for each time point

reached to a level of $20.67 \%$, and significantly higher than those in the DCD and the control $(P<0.05)$. Field experiment showed that the DMPP and DMS treatments separately showed a grain yield level of $12.14 \mathrm{tha}^{-1}$ and $12.25 \mathrm{tha}^{-1}$, which revealed an increase of more than $20 \%$ comparing to the control. In addition, compared with the control, the partial productivity and agronomy utilization rate of nitrogen fertilizer in the DMS treatment were increased by more than $24 \%$ and $300 \%$, respectively, indicating that the DMS treatment overall revealed the best effects in improving nitrogen use efficiency (Table 4).

Studies showed that nitrification inhibitors demonstrate different nitrification suppression effects in diverse soils (Chen et al. 2008; Shi et al. 2016a, b). As typical nitrification inhibitors, DMPP and DCD have been widely applied to improve nitrogen use efficiency, thus increasing crop yields (Pasda et al. 2001; Guillaumes and Villar 2004; Fangueiro et al. 2009; Wang et al. 2016; Souza et al. 2020; Wallace et al. 2020). In this study, both the DMPP and DCD treatments significantly increased the accumulation of ammonium nitrogen and raised wheat or maize yields because of an increasing nitrogen use efficiency comparing to the control. However, the novel DMS nitrification inhibitor demonstrated the long-lasting effects in improving nitrogen use efficiency and crop yield, indicating that a novel synthesized DMS nitrification inhibitor could function in suppressing nitrification of ammonium and be suitable for application in black soil of northeast China.

Usually, the effect of nitrification inhibitor is mainly controlled by the biological activity and survival period of itself in the soil, while the biological activity and survival period are affected by soil temperature, humidity, and microbial community, thus resulting in unstable and variable effects of nitrification inhibitors (McGeough et al. 2016; Vilas et al. 2019). As previously reported, the DCD nitrification inhibitor demonstrated a lower biological activity and survivability than the DMPP (Supplemental material Fig. S1). Azam et al. (2001) found that maintaining the same effects of nitrification inhibition requires higher dosages of nitrification inhibitor as demonstrated in both this trial and the previous report (Chen et al. 2015). Additionally, DCD is a kind of nitrification inhibitor with vegetable toxic; overuse of DCD easily triggers the damage to the plants, thus limiting its application in the agricultural production (Macadam et al. 2003).

Although DMPP is an ideal nitrification inhibitor and presently has been applied in agricultural production because of an advantage in suppressing nitrification, its unstable physical and chemical properties still limit its wide application. Particularly, high-dosage application of more than $100 \mathrm{mg} \mathrm{kg}^{-1}$ in soil usually triggers toxicity to the plants (Rodrigues et al. 2018). Importantly, a large application of DMPP results in an increase in costeffectiveness because of more than tenfold price comparing to the DCD. In this study, DMS is a novel nitrification inhibitor which was amended by improving DMPP; both DMS and DMPP contain the same core group 3,4-dimethylpyrazole nitrification suppression, not increasing negative effect and costs because DMS was produced by a reaction between zinc sulfate and DMP, while DMPP is produced by DMP reacting with phosphoric acid (Chen et al. 2015). Therefore, both DMPP and DMS have a similar production process, while zinc sulfate and phosphoric acid have no cost differences basically. Our study indicates that a novel DMS nitrification inhibitor revealed more strong effect in suppressing nitrification of ammonium and maintained a long-lasting alleviation role in releasing rates in soil because of its insoluble in water comparing to the DMPP (Supplementary material Table S1). Compared to DMPP, DMS with a neutral $\mathrm{pH}$ has better stability in soil and is slightly soluble in water. Importantly, DMS reveals a sustainable nitrification inhibition effect, and no potential side effect was observed in soil. Therefore, we believe that DMS is a reasonable optimization and improvement of DMPP without increasing cost. Both soil incubation and field experiment showed that DMS exhibited stronger bactericidal effects than DMPP after 58 days or 83 days, indicating that high accumulation of soil ammonium nitrogen in soils demonstrated a strong nitrification suppression role of DMS, thus increasing nitrogen use efficiency and crop yield by reducing the loss of nitrogen. 


\section{Conclusion}

In summary, this study confirms that a novel amended DMS nitrification inhibitor revealed an important regulatory role in suppressing the conversion of ammonium nitrogen to nitrate nitrogen, and significantly improved nitrogen fertilizer use efficiency by inhibiting the activity of AOB in soils. DMS nitrification inhibitor is suitable for application in the black soil region in northeast of China. This study provided an insight into the regulatory role of a novel DMS nitrification inhibitor in enhancing the efficiency of nitrogen fertilizer, directly proving that high biological activity and long survival period of DMS in soil are two important factors maintaining sustainable nitrification inhibition effects, while prolonging the survival of nitrification inhibitor in soil is required for effectively lowering the loss of nitrogen in soil.

Supplementary information The online version contains supplementary material available at https://doi.org/10.1007/s11368-021-03118-3.

Author contribution G.C., Z.D., and H.X. conceived and designed the experiment; G.C., Z.D., and W.Y. analyzed the data, and G.C., Z.D., and H.X wrote the paper. All authors read and approved the final manuscript.

Funding This work was supported by the National Key Research and Development Program of China (Grant No. 2018YFD0300308) and the National Natural Science Foundation of China (Grant No. 31471940).

\section{Declarations}

Conflict of interest The authors declare no competing interests.

Open Access This article is licensed under a Creative Commons Attribution 4.0 International License, which permits use, sharing, adaptation, distribution and reproduction in any medium or format, as long as you give appropriate credit to the original author(s) and the source, provide a link to the Creative Commons licence, and indicate if changes were made. The images or other third party material in this article are included in the article's Creative Commons licence, unless indicated otherwise in a credit line to the material. If material is not included in the article's Creative Commons licence and your intended use is not permitted by statutory regulation or exceeds the permitted use, you will need to obtain permission directly from the copyright holder. To view a copy of this licence, visit http://creativecommons.org/licenses/by/4.0/.

\section{References}

Adams CJ, Kurawa MA, Orpen AG (2010) Coordination chemistry in the solid state: synthesis and interconversion of pyrazolium salts, pyrazole complexes, and pyrazolate MOFs. Dalton Trans 39:6974-6984. https://doi.org/10.1039/c0dt00195c

Asher C, Grundon N, Menzies N (2002) Getting ready to run pot experiments. In: Asher C, Grundon N, Menzies N(ed) How to unravel and solve soil fertility problems, ACIAR Monograph, No.83, Canberra, pp 25-36
Azam F, Benckiser G, Müller C, Ottow J (2001) Release, movement and recovery of 3, 4-dimethylpyrazole phosphate (DMPP), ammonium, and nitrate from stabilized nitrogen fertilizer granules in a silty clay soil under laboratory conditions. Biol Fertil Soils 34:118-125. https://doi.org/10.1007/s003740100384

Chen D, Freney JR, Rochester I, Constable GA, Mosier AR, Chalk PM (2008) Evaluation of a polyolefin coated urea (Meister) as a fertilizer for irrigated cotton. Nutr Cycl Agroecosyst 81:245-254. https://doi.org/10.1007/s10705-007-9160-0

Chen Q, Qi L, Bi Q, Dai P, Sun D, Sun C, Liu W, Lu L, Ni W, Lin X (2015) Comparative effects of 3, 4-dimethylpyrazole phosphate (DMPP) and dicyandiamide (DCD) on ammonia-oxidizing bacteria and archaea in a vegetable soil. Appl Microbiol Biotechnol 99:477-487. https://doi.org/10.1007/s00253-014-6026-7

Chen H, Yin C, Fan X, Ye M, Peng H, Li T, Zhao Y, Wakelin SA, Chu G, Liang Y (2019) Reduction of $\mathrm{N}_{2} \mathrm{O}$ emission by biochar and/or 3, 4-dimethylpyrazole phosphate (DMPP) is closely linked to soil ammonia oxidizing bacteria and nosZI- $\mathrm{N}_{2} \mathrm{O}$ reducer populations. Sci Total Environ 694:133658. https://doi.org/10.1016/j.scitotenv. 2019.133658

Davies DM, Williams PJ (1995) The effect of the nitrification inhibitor dicyandiamide on nitrate leaching and ammonia volatilization: a U.K. nitrate sensitive areas perspective. J Environ Manag 45:263-272. https://doi.org/10.1006/jema.1995.0074

Di HJ, Cameron KC (2011) Inhibition of ammonium oxidation by a liquid formulation of 3, 4-dimethylpyrazole phosphate (DMPP) compared with a dicyandiamide (DCD) solution in six new Zealand grazed grassland soils. J Soils Sediments 11:1032-1039. https://doi.org/10.1007/s11368-011-0372-1

Di HJ, Cameron KC (2012) How does the application of different nitrification inhibitors affect nitrous oxide emissions and nitrate leaching from cow urine in grazed pastures? Soil Use Manag 28:54-61. https://doi.org/10.1111/j.1475-2743.2011.00373.x

Ding Y, Huang X, Li Y, Liu H, Zhang Q, Liu X, Xu J, Di H (2021) Nitrate leaching losses mitigated with intercropping of deeprooted and shallow-rooted plants. J Soils Sediments 21:364-375. https://doi.org/10.1007/s11368-020-02733-w

Erisman J, Sutton M, Galloway J, Klimont Z, Winiwarter W (2008) How a century of ammonia synthesis changed the world. Nat Geosci 1:636-639. https://doi.org/10.1038/ngeo325

Fan X, Yin C, Chen H, Ye M, Zhao Y, Li T, Wakelin SA, Liang Y (2019) The efficacy of 3, 4-dimethylpyrazole phosphate on $\mathrm{N}_{2} \mathrm{O}$ emissions is linked to niche differentiation of ammonia oxidizing archaea and bacteria across four arable soils. Soil Biol Biochem 130:82-93. https://doi.org/10.1016/j.soilbio.2018.11.027

Fangueiro D, Fernandes A, Coutinho J, Moreira N, Trindade H (2009) Influence of two nitrification inhibitors (DCD and DMPP) on annual ryegrass yield and soil mineral $\mathrm{N}$ dynamics after incorporation with cattle slurry. Commun Soil Sci Plant Anal 40:33873398. https://doi.org/10.1080/00103620903325976

Florio A, Clark IM, Hirsch PR, Jhurreea D, Benedetti A (2014) Effects of the nitrification inhibitor 3, 4-dimethylpyrazole phosphate (DMPP) on abundance and activity of ammonia oxidizers in soil. Biol Fertil Soils 50:795-807. https://doi.org/10.1007/ s00374-014-0897-8

Galloway JN, Dentener FJ, Capone DG, Boyer EW, Howarth RW, Seitzinger SP, Asner GP, Cleveland CC, Green PA, Holland EA, Karl DM, Michaels AF, Porter JH, Townsend AR, Vöosmarty CJ (2004) Nitrogen cycles: past, present, and future. Biogeochemistry 70:153-226. https://doi.org/10.1007/s10533-004-0370-0

Gao J, Luo J, Lindsey S, Shi Y, Sun Z, Wei Z, Wang L (2021) Benefits and risks for the environment and crop production with application of nitrification inhibitors in China. J Soil Sci Plant Nutr 21:497-512. https://doi.org/10.1007/s42729-020-00378-9

Ghani A, Dexter M, Carran RA, Theobald PW (2007) Dissolved organic nitrogen and carbon in pastoral soils: the New Zealand 
experience. Eur J Soil Sci 58:832-843. https://doi.org/10.1111/j. 1365-2389.2006.00873.x

Gong P, Zhang L, Wu Z, Chen Z, Chen L (2013) Responses of ammonia-oxidizing bacteria and archaea in two agricultural soils to nitrification inhibitors DCD and DMPP: a pot experiment. Pedosphere 23:729-739. https://doi.org/10.1016/s1002-0160(13) 60065-X

Gu Z, Xie Y, Gao Y, Ren X, Cheng C, Wang S (2018) Quantitative assessment of soil productivity and predicted impacts of water erosion in the black soil region of northeastern China. Sci Total Environ 637:706-716. https://doi.org/10.1016/j.scitotenv.2018. 05.061

Guillaumes E, Villar JM (2004) Effects of DMPP [3,4-dimethylpyrozole phosphate] on the growth and chemical composition of ryegrass (Lolium perenne L.) raised on calcareous soil. Span J Agric Res 2:588-596. https://doi.org/10.5424/sjar/2004024-115

He J, Shen J, Zhang L, Zhu Y, Zheng Y, Xu M, Di H (2007) Quantitative analyses of the abundance and composition of ammoniaoxidizing bacteria and ammonia-oxidizing archaea of a Chinese upland red soil under long-term fertilization practices. Environ Microbiol 9:3152-3152. https://doi.org/10.1111/j.1462-2920. 2007.01358.x

Hink L, Nicol GW, Prosser JI (2017) Archaea produce lower yields of $\mathrm{N}_{2} \mathrm{O}$ than bacteria during aerobic ammonia oxidation in soil. Environ Microbiol 19:4829-4837. https://doi.org/10.1111/14622920.13282

Isaac R A, Kerber JD (1971) Atomic absorption and flame photometry: techniques and uses in soil, plant, and water analysis. In: Walsh LM (ed) Instrumental Methods for Analysis of Soils and Plant Tissue. Wiley Online Library, The Soil Science Society of America, pp 17-37. https://doi.org/10.2136/1971.instrumentalmethods.c2

Kleineidam K, Košmrlj K, Kublik S, Palmer I, Pfab H, Ruser R, Fiedler $S$, Schloter M (2011) Influence of the nitrification inhibitor 3, 4-dimethylpyrazole phosphate (DMPP) on ammonia-oxidizing bacteria and archaea in rhizosphere and bulk soil. Chemosphere 84:182-186. https://doi.org/10.1016/j.chemosphere.2011.02.086

Li S, Wang Z, Hu T, Gao Y, Stewart B, Sparks D (2009) Nitrogen in dryland soils of China and its management. Adv Agron 101:123181. https://doi.org/10.1016/s0065-2113(08)00803-1

Liang A, Yang X, Zhang X, Chen X, Mclaughlin NB, Wei S, Zhang Y, Jia S, Zhang S (2016) Changes in soil organic carbon stocks under 10-year conservation tillage on a Black soil in Northeast China. J Agric Sci 154:1425-1436. https://doi.org/10.1017/s002185961500132x

Limpiyakorn T, Sonthiphand P, Rongsayamanont C, Polprasert C (2011) Abundance of amoA genes of ammonia-oxidizing archaea and bacteria in activated sludge of full-scale wastewater treatment plants. Bioresour Technol 102:3694-3701. https://doi.org/ 10.1016/j.biortech.2010.11.085

Liu X, Vitousek P, Chang Y, Zhang W, Matson P, Zhang F (2016) Evidence for a historic change occurring in China. Environ Sci Technol 50:505-506. https://doi.org/10.1021/acs.est.5b05972

Macadam XMB, del Prado A, Merino P, Estavillo JM, Pinto M, González-Murua C (2003) Dicyandiamide and 3, 4-dimethyl pyrazole phosphate decrease $\mathrm{N}_{2} \mathrm{O}$ emissions from grassland but dicyandiamide produces deleterious effects in clover. J Plant Physiol 160:1517-1523. https://doi.org/10.1078/0176-1617-01006

Menéndez S, Merino P, Pinto M, González-Murua C, Estavillo JM (2006) 3,4-Dimethylpyrazol phosphate effect on nitrous oxide, nitric oxide, ammonia, and carbon dioxide emissions from grasslands. J Environ Qual 35:973-981. https://doi.org/10.2134/jeq2005.0320

McGeough KL, Watson CJ, Müller C, Laughlin RJ, Chadwick DR (2016) Evidence that the efficacy of the nitrification inhibitor dicyandiamide (DCD) is affected by soil properties in UK soils. Soil Biol Biochem 94:222-232. https://doi.org/10.1016/j.soilbio.2015.11.017

Mueller ND, Lassaletta L, Runck BC, Billen G, Garnier J, Gerber JS (2017) Declining spatial efficiency of global cropland nitrogen allocation. Global Biogeochem Cycles 31:245-257. https://doi. org/10.1002/2016gb005515

Musiani F, Broll V, Evangelisti E, Ciurli S (2020) The model structure of the copper-dependent ammonia monooxygenase. J Biol Inorg Chem 25:995-1007. https://doi.org/10.1007/s00775-020-01820-0

O'Callaghan M, Gerard EM, Carter PE, Lardner R, Sarathchandra U, Burch G, Ghan A, Bell N (2010) Effect of the nitrification inhibitor dicyandiamide (DCD) on microbial communities in a pasture soil amended with bovine urine. Soil Biol Biochem 42:14251436. https://doi.org/10.1016/j.soilbio.2010.05.003

Pasda G, Hähndel R, Zerulla W (2001) Effect of fertilizers with the new nitrification inhibitor DMPP (3, 4-dimethylpyrazole phosphate) on yield and quality of agricultural and horticultural crops. Biol Fertil Soils 34:85-97. https://doi.org/10.1007/s003740100381

Rodrigues JM, Lasa B, Aparicio-Tejo PM, González-Murua C, Marino D (2018) 3,4-Dimethylpyrazole phosphate and 2-(N-3,4-dimethyl1H-pyrazol-1-yl) succinic acid isomeric mixture nitrification inhibitors: quantification in plant tissues and toxicity assays. Sci Total Environ 624:1180-1186. https://doi.org/10.1016/j.scitotenv.2017.12.241

Shen J, Zhang L, Zhu Y, Zhang J, He J (2008) Abundance and composition of ammonia-oxidizing bacteria and ammonia-oxidizing archaea communities of an alkaline sandy loam. Environ Microbiol 10:1601-1611. https://doi.org/10.1111/j.1462-2920.2008.01578.x

Shi X, Hu H, He J, Chen D, Suter HC (2016a) Effects of 3, 4-dimethylpyrazole phosphate (DMPP) on nitrification and the abundance and community composition of soil ammonia oxidizers in three land uses. Biol Fertil Soils 52:927-939. https://doi.org/10.1007/ s00374-016-1131-7

Shi X, Hu H, Müller C, He J, Chen D, Suter HC (2016b) Effects of the nitrification inhibitor 3, 4-dimethylpyrazole phosphate on nitrification and nitrifiers in two contrasting agricultural soils. Appl Environ Microbiol 82:5236-5248. https://doi.org/10.1128/aem. 01031-16

Shi X, Hu H, Zhu-Barker X, Hayden H, Wang J, Suter H, Chen D, He $\mathbf{J}$ (2017) Nitrifier-induced denitrification is an important source of soil nitrous oxide and can be inhibited by a nitrification inhibitor 3, 4-dimethylpyrazole phosphate. Environ Microbiol 19:48514865. https://doi.org/10.1111/1462-2920.13872

Souza EF, Soratto RP, Sandaña P, Venterea RT, Rosen CJ (2020) Split application of stabilized ammonium nitrate improved potato yield and nitrogen-use efficiency with reduced application rate in tropical sandy soils. Field Crop Res 254:107847. https://doi.org/10. 1016/j.fcr.2020.107847

Sutton MA, Howard CM, Erisman JW, Billen G, Bleeker A, Grennfelt P, Grizzetti B (2011) The European nitrogen assessment: sources, effects and policy perspectives. Cambridge University, New York

Tan KH (2005) Soil sampling, preparation, and analysis. Marcel Dekker Inc, New York

Ti C, Yan X (2020) Nitrogen regulation in China's agricultural systems. In: Liu X, Du E (ed). Atmospheric Reactive Nitrogen in China, Springer, Singapore, pp 297-309

Tong D, Xu R (2012) Effects of urea and $\left(\mathrm{NH}_{4}\right)_{2} \mathrm{SO}_{4}$ on nitrification and acidification of Ultisols from Southern China. J Environ Sci 24:682-689. https://doi.org/10.1016/s1001-0742(11)60832-2

Vilas MP, Verburg K, Thorburn PJ, Probert ME, Bonnett GD (2019) A framework for analysing nitrification inhibition: a case study on 3, 4-dimethylpyrazole phosphate (DMPP). Sci Total Environ 672:846-854. https://doi.org/10.1016/j.scitotenv.2019.03.462

Wallace AJ, Armstrong RD, Grace PR, Scheer C, Partington DL (2020) Nitrogen use efficiency of $15 \mathrm{~N}$ urea applied to wheat based on fertilizer timing and use of inhibitors. Nutr Cycl Agroecosyst 116:41-56. https://doi.org/10.1007/s10705-019-10028-x

Wang W, Park G, Reeves S, Zahmel M, Heenan M, Salter B (2016) Nitrous oxide emission and fertilizer nitrogen efficiency in a tropical sugarcane cropping system applied with different formulations of urea. Soil Res 54:572-584. https://doi.org/10.1071/sr15314 
Wang Y, Cheng Y, Chen K, Tsay Y (2018) Nitrate transport, signaling, and use efficiency. Annu Rev Plant Biol 69:85-122. https://doi. org/10.1146/annurev-arplant-042817-040056

Wang M, Wang S, Long X, Zhuang L, Zhao X, Jia Z, Zhu G (2019) High contribution of ammonia-oxidizing archaea (AOA) to ammonia oxidation related to a potential active AOA species in various arable land soils. J Soils Sediments 19:1077-1087. https:// doi.org/10.1007/s11368-018-2108-y

Wu S, Wu L, Shi Q, Wang Z, Chen X, Li Y (2007) Effects of a new nitrification inhibitor 3, 4-dimethylpyrazole phosphate (DMPP) on nitrate and potassium leaching in two soils. J Environ Sci 19:841847. https://doi.org/10.1016/s1001-0742(07)60140-5

Xia W, Zhang C, Zeng X, Feng Y, Weng J, Lin X, Zhu J, Xiong Z, Xu J, Cai Z, Jia Z (2011) Autotrophic growth of nitrifying community in an agricultural soil. ISME J 5:1226-1236. https://doi.org/10. 1038/ismej.2011.5

Xu X, Huang Y, Zhou L, Huang G, Cleemput O (2001) Effect of dicyandiamide and hydroquinone on the transformation of ureanitrogen-15 in soil cropped to wheat. Biol Fertil Soils 34:286-290. https://doi.org/10.1007/s003740100393

Yu C, Huang X, Chen H, Godfray HCJ, Wright JS, Hall JW, Gong P, Ni S, Qiao S, Huang G, Xiao Y, Zhang J, Feng Z, Ju X, Ciais P, Stenseth NC, Hessen DO, Sun Z, Yu L, Cai W, Fu H, Huang X, Zhang C, Liu H, Taylor J (2019) Managing nitrogen to restore water quality in China. Nature 567:516-520. https://doi.org/10.1038/ s41586-019-1001-1

Zerulla W, Barth T, Dressel J, Erhardt K, von Locquenghien KH, Pasda G, Wissemeier RM, AH, (2001) 3, 4-Dimethylpyrazole phosphate
(DMPP) — a new nitrification inhibitor for agriculture and horticulture. Biol Fertil Soils 34:79-84. https://doi.org/10.1007/s003740100380

Zhang X, Davidson E, Mauzerall D, Searchinger T, Dumas P, Shen Y (2015) Managing nitrogen for sustainable development. Nature 528:51-59. https://doi.org/10.1038/nature15743

Zhang S, Zheng Q, Noll L, Hu Y, Wanek W (2019) Environmental effects on soil microbial nitrogen use efficiency are controlled by allocation of organic nitrogen to microbial growth and regulate gross N mineralization. Soil Biol Biochem 135:304-315. https:// doi.org/10.1016/j.soilbio.2019.05.019

Zhou X, Wang S, Ma S, Zheng X, Wang Z, Lu C (2020) Effects of commonly used nitrification inhibitors-dicyandiamide (DCD), 3, 4-dimethylpyrazole phosphate (DMPP), and nitrapyrin-on soil nitrogen dynamics and nitrifiers in three typical paddy soils. Geoderma 380:114637. https://doi.org/10.1016/j.geoderma.2020. 114637

Zhu Q, Liu X, Hao T, Zeng M, Shen J, Zhang F, de Vries W (2018) Modeling soil acidification in typical Chinese cropping systems. Sci Total Environ 613:1339-1348. https://doi.org/10.1016/j. scitotenv.2017.06.257

Publisher's Note Springer Nature remains neutral with regard to jurisdictional claims in published maps and institutional affiliations. 